\title{
A indústria de calçados de Nova Serrana (MG)
}

\author{
Wilson Surigan \\ Professor do Instituto de Geociências da Unicamp \\ João Furtado \\ Professor da UNESP e da Escola Politécnica da USP
}

\section{Palauras-chave}

sistemas locais de produção, economia mineira, indústria de calçados, Nova Serrana.

Classificação JEL R12, L67, L52.

\begin{abstract}
Key words
local production systems, shoe manufacturing industry, Nova Serrana (Minas Gerais).
\end{abstract}

JEL Classification R12, L67, I 52 .

\section{Resumo}

Utilizando resultados de trabalho estatístico com base nos dados da Relação Anual de Informações Sociais (RAIS), que permitem caracterizar a indústria de calçados de Nova Serrana (MG) como um sistema local de produção, e nos resultados de pesquisa de campo efetuada em abril de 2002, quando foram realizadas entrevistas e visitas em empresas e instituições locais, o artigo estuda o sistema local de produção de Nova Serrana tanto em termos do sistema como um todo quanto das empresas e instituições que o compõem. O objetivo é produzir, nesses dois níveis de análise, evidências que possam orientar ações públicas e privadas, visando ao aprimoramento do sistema e das empresas locais em duas esferas: (1) produtiva e tecnológica, em seus vários desdobramentos, e (2) institucional e organizacional. Para isso, caracteriza e dimensiona primeiramente o sistema local em termos de sua localização e região de influência, sua logística, população e empregos gerados, história e evolução, estrutura de produção, instituições de apoio, contexto social, cultural e político. Em seguida, caracteriza as empresas em termos de tamanho e quanto a: desenvolvimento de produto, sistemas de comercialização, relações cooperativas, interações com fornecedores, fontes de informação para desenvolvimento de produtos e sobre mercados e processos de fabricação, práticas e políticas quanto à qualidade, ao financiamento e a outros aspectos pertinentes ao caso em estudo. Por fim, ressalta os problemas mais relevantes que podem ser objeto de políticas públicas e/ou de ações conjuntas das empresas e instituições locais.
Renato Garcia

Professor da Escola Politécnica da USP

Sérgio E. K. Sampaio

Mestrando em Desenvolvimento Econômico - UFPR 


\section{1_Introdução}

O município de Nova Serrana notabilizou-se recentemente por concentrar grande número de empresas fabricantes de calçados, notadamente tênis e seus componentes. Essas empresas respondiam, em 2002 , por $55 \%$ da produção nacional de tênis e geravam entre 20 e 25 mil empregos diretos e indiretos, segundo estimativas do Sindicato da Indústria do Calçado de Nova Serrana (Sindinova). Dada sua relevância, não só do ponto de vista local/regional como também de sua participação na indústria brasileira de calçados, foi objeto de um dos estudos de casos realizados no âmbito do projeto de pesquisa Sistemas Produtivos Locais na Indústria Calçadista Brasileira: avaliação e sugestões de políticas, realizado em 20012003 com apoio financeiro do CNPq, do qual este artigo foi derivado.

O artigo apóia-se em duas fontes de dados e informações:

1. indicadores quantitativos elaborados com base nos dados da Relação Anual de Informações Sociais (RAIS);

2. resultados da pesquisa de campo efetuada em abril de 2002, quando foram realizadas entrevistas e visitas em empresas e instituições locais.
Os indicadores são: o Quociente Locacional (QL) e o coeficiente de Gini Locacional (GL), cuja metodologia já foi apresentada em trabalhos anteriores dos autores, ${ }^{1}$ e os números absolutos de empregos e estabelecimentos por classes de indústria (CNAE 4 dígitos) para a microrregião de Divinópolis e o município de Nova Serrana. Esses indicadores permitem caracterizar Nova Serrana como um sistema local de produção. ${ }^{2}$ Os resultados da pesquisa de campo, por sua vez, são constituídos por dados e informações coletados e sistematizados com base nas entrevistas e nas visitas. $\mathrm{Na}$ impossibilidade de aplicar questionários por amostragem estatística, procurou-se selecionar um grupo de empresas que fosse representativo do universo local composto majoritariamente por micro, pequenas e médias empresas. A maioria das empresas visitadas foi fundada nas décadas de 1980 e 1990, emprega entre 20 e 110 pessoas (sem contar o emprego gerado em atividades terceirizadas), fabrica tênis adulto/infantil e esportivos (uma delas é fabricante de sandálias), e vende predominantemente no mercado interno. As entrevistas e as visitas em instituições locais incluíram o Sindicato da Indústria (Sindinova) e o Centro de Desenvolvimento Empresarial, que abriga um centro de modelagem de calçados e um laborató-
1 Ver particularmente

Suzigan et al. (2003), publicado pela Nova Economia.

2 O significado do conceito de sistema local de produção aqui adotado é praticamente o mesmo do conceito de "sistema produtivo e inovativo local" adotado pela RedeSist, que o distingue do conceito de "arranjo produtivo local”. Este apresenta vínculos incipientes entre atores locais (Cassiolato e Lastres, 2003). Optamos, porém, pela utilização de um conceito único e simples de sistema local de produção, seguindo a tradição de estudos de pesquisadores italianos (ver, por exemplo, Lombardi, 2003) e considerando que as distinções entre sistemas resumem-se a graus variados de desenvolvimento, de integração da cadeia produtiva, de presença de indústrias correlatas, de articulação e interação entre agentes e instituições locais, e de capacidades sistêmicas para a inovação. 
rio de ensaios e testes, além de coordenar vários tipos de assessoria e serviços empresariais e realizar cursos e treinamentos.

De acordo com a metodologia adotada, o sistema local de produção de Nova Serrana é analisado nas seções seguintes tanto em termos do sistema como um todo quanto das empresas que o compõem. O objetivo é produzir evidências, nesses dois níveis de análise, que possam servir de orientação a ações públicas e privadas, visando ao aprimoramento do sistema e das empresas locais em duas esferas:

1. produtiva e tecnológica, em seus vários desdobramentos;

2. institucional e organizacional.

Procura-se, assim, caracterizar e dimensionar primeiramente o sistema local em termos de sua localização e região de influência, sua logística, população e empregos gerados, história e evolução, estrutura de produção, instituições de apoio, contexto social, cultural e político. Em seguida, procura-se caracterizar as empresas quanto a: desenvolvimento de produto, sistemas de comercialização, relações cooperativas e associativismo, relações entre fabricantes de calçados e seus fornecedores, fontes de informação para desenvolvimento de produtos e sobre mercados e processos de fabricação, práticas e políticas quanto à qualidade, ao financiamento e a outros aspectos perti- nentes ao caso em estudo. Por fim, ressaltam-se os problemas mais relevantes que podem ser objeto de políticas públicas e/ou de ações conjuntas das empresas e instituições locais.

\section{2_Localização e região de influência}

Nova Serrana está localizada na região Centro-Oeste do Estado de Minas Gerais, às margens da BR - 262, a $112 \mathrm{~km}$ de Belo Horizonte e a $42 \mathrm{~km}$ de Divinópolis, cidade mais importante e que dá nome à microrregião que contém o município de Nova Serrana (ver Mapa 1). As atividades da indústria de calçados local se ramificam por vários municípios vizinhos, que não só participam do processo de fabricação de calçados, como também fornecem mãode-obra para a indústria de Nova Serrana. As etapas terceirizadas do processo deprodução são distribuídas por municípios num entorno de 30 a 40 quilômetros, incluindo Divinópolis, São Gonçalo do Pará, Itaúna e Perdigão, na microrregião de Divinópolis, além de outros de microrregiões circunvizinhas, incluindo os municípios de Oliveira, Bom Despacho, Pitangui e Pará de Minas. Ademais, segundo informações de empresários locais, mais de cem ônibus partem diariamente desses e de outros municípios levando trabalhadores para a indústria de Nova Serrana. 
Mapa 1_Localização e região de influência da indústria de calçados de Nova Serrana, MG

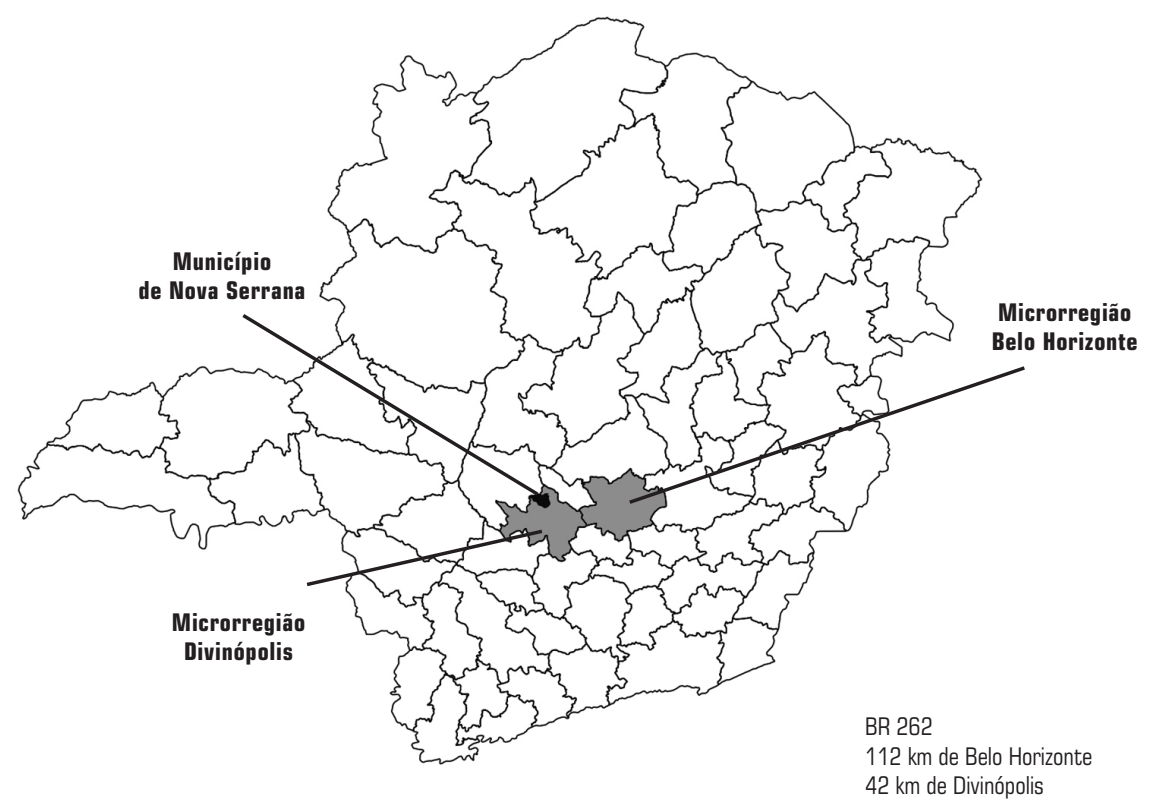

Fonte: Elaboração própria.

Alguns dos municípios vizinhos, entre os quais Divinópolis, Perdigão e São Gonçalo do Pará, também desenvolveram, por influência do pólo de Nova Serrana, sua própria indústria de calçados. Perdigão, por exemplo, concentra atualmente cerca de 100 pequenas empresas, na maioria familiares, que fabricam produtos similares aos de Nova Serrana. Segundo o presidente do Sindinova, Júnior César Silva, em entrevista a uma revista local, não existe preocupação quanto a uma eventual concorrência com Nova
Serrana; ao contrário, o novo pólo poderá contribuir para o crescimento e o fortalecimento da região, atraindo mais compradores, empresas fornecedoras de componentes e apoio do setor público.

\section{Logística e infra-estrutura ${ }^{3}$}

A localização de Nova Serrana às margens da BR-262 é bastante satisfatória para as empresas locais do ponto de vista de acesso a mercados para seus produtos, bem como para compra de matérias-

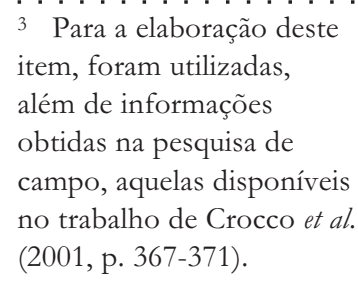


primas e componentes não produzidos localmente. Os principais mercados são os dos grandes centros urbanos mais próximos (Belo Horizonte, São Paulo e Rio de Janeiro), com os quais há ligações rodoviárias satisfatórias, mas há também condições razoáveis de acesso por rodovias a outros mercados importantes para a produção local, tais como o interior do Estado e as regiões Nordeste e CentroOeste do País. Essa mesma infra-estrutura rodoviária permite outra importante forma de comercialização da produção local, ou seja, as vendas diretas realizadas nas próprias fábricas.

Outros componentes da infra-estrutura física, como o suprimento de energia elétrica e os serviços de telecomunicações, apresentam condições adequadas em função de melhoramentos recentes. Dados levantados pelo Sindinova mostram que a Cemig atende 11.680 residências, 1.429 estabelecimentos industriais e 1.244 estabelecimentos comerciais no município; revelam também que há 11.000 terminais de telefonia fixa instalados e 3.000 aparelhos de telefonia móvel habilitados.

Mas a infra-estrutura urbana de modo geral é bastante deficiente, sobretudo pela falta de um planejamento que discipline a instalação de fábricas em áreas próprias. A cidade cresceu muito rapi- damente, e centenas de fábricas foram sendo instaladas por toda a área urbana, criando um ambiente de convivência "promíscua" entre fábricas de calçados ou componentes e residências.

Há também notórias deficiências no ensino médio e superior, que se refletem na insuficiência de capacitação técnica e gerencial local. É insuficiente também a oferta de cursos técnicos, o que acarreta falta de mão-de-obra especializada, particularmente na operação de pesponto, bem como de alguns serviços técnicos especializados, tais como modelagem, design e serviços financeiros.

\section{4_População local e empregos gerados pela indústria de calçados}

O município de Nova Serrana tem pouco mais de 40 mil habitantes, e sua população vem crescendo a uma taxa extremamente alta (cerca de 8\% ao ano, segundo dados divulgados pelo Sindinova), o que denota significativo movimento migratório estimulado pela criação de emprego nas atividades econômicas locais. Os dados da RAIS de 2002, referentes à microrregião de Divinópolis, indicam um total de 9.972 empregos formais nas atividades relacionadas com a produ- 
ção de calçados na região. Entretanto, estimativas realizadas pelo Sindinova, em 2002 , indicam que a indústria de calçados gera cerca de 15 mil empregos diretos, e um total de 20 mil a 25 mil empregos, quando considerados também os indiretos, os formais e os informais.

Levando-se em conta a dimensão da população local, pode-se perceber que há de fato necessidade de atrair mão-deobra dos municípios vizinhos, uma vez que a proporção da população local que constitui a força de trabalho é evidentemente insuficiente. Isso comprova o que foi dito antes, que cerca de uma centena de ônibus vai diariamente a Nova Serrana levando trabalhadores de municípios vizinhos. E ainda assim, segundo os empresários entrevistados, há falta de mãode-obra, sobretudo com qualificações mais elevadas, por exemplo, para as atividades de pesponto, como já dito.

\section{5_História: condições iniciais e evolução}

A organização da produção de calçados como atividade industrial em Nova Serrana começou na década de 1950. Anteriormente, as atividades agrícolas e de pecuária leiteira parecem ter criado as condições iniciais para o surgimento da produção artesanal de artigos de couro e botinas rústicas. $\mathrm{O}$ aprendizado na fabricação de calçados, porém, começou no início da década de 1950, quando um dos pioneiros da indústria "foi para Bom Despacho aprender o oficio de sapateiro" (Almeida, 1996). Na segunda metade da década, após a emancipação do município, surgiram as primeiras fábricas e dois pequenos curtumes. O calçado produzido era um tipo de botina de couro com solado de pneu laminado.

As dificuldades de transporte e de suprimento de energia, entretanto, restringiam o crescimento da produção. Somente após a ligação à rede de energia elétrica da Cemig, em 1967, e a abertura ao tráfego da BR-262, em 1969, é que a indústria local prosperou. No início dos anos 1970, já havia 48 pequenas fábricas de calçados em operação, todas produzindo calçados de couro (Almeida, 1996). Com a chegada das primeiras agências bancárias e a instalação de rede de telefonia, completou-se a infra-estrutura mínima necessária para a expansão da indústria.

O primeiro surto de rápido crescimento da indústria de calçados de Nova Serrana ocorreu entre os meados das décadas de 1970 e 1980. Após uma viagem dos fabricantes locais a Novo Hamburgo (RS), em 1971, viagem essa que, segundo 
$\cdots \ldots \ldots \ldots$

4 Crocco et al. (2001, p. 344, nota n. 15) afirmam que o primeiro empreendimento produtor de tênis em Nova Serrana fabricava tênis falsificados com marcas de grifes famosas.
Almeida (1996), "constituiu-se em mola propulsora dos eventos futuros", e a fundação da Associação Comercial e Industrial de Nova Serrana (ACINS), em 1974, os fabricantes locais de calçados se organizaram, para intensificar o aprendizado, incorporar novas tecnologias e melhorar a qualidade dos produtos e o gerenciamento das empresas. A produção diversificou-se com a fabricação de mocassins e sandálias de couro. Das 48 fábricas existentes em 1972, pulou-se para cerca de $400 \mathrm{em} 1985$. O auge do crescimento parece ter ocorrido no ano de 1986, com o Plano Cruzado, mas a crise subseqüente, que marcou o fim do plano, atingiu profundamente a indústria local.

É nessa época que se verifica uma mudança radical na trajetória da indústria de calçados de Nova Serrana, isto é, o início da fabricação de tênis. Essa mudança representa verdadeira bifurcação na evolução da indústria por três razões:

1. muda o patamar de taxas de crescimento da produção;

2. altera radicalmente a base tecnológica da produção;

3. modifica também a forma de organização da produção industrial.

A pergunta que intriga é a seguinte: o que levou a indústria local, que já havia acu- mulado significativo conhecimento na fabricação de calçados de couro, a mudar radicalmente o produto, a base tecnológica e a organização industrial?

Crocco et al. (2001, p. 344) oferecem duas justificativas relevantes:

1. o aproveitamento pelos fabricantes locais da "janela de oportunidade" oferecida pelo boom do material sintético;

2. a simplicidade na fabricação de tênis em comparação ao calçado de couro.

Sem entrar no mérito dessas justificativas, mesmo que verdadeiras, elas não respondem à pergunta feita acima. O que parece ter ocorrido é que, em reação à crise dos anos oitenta, um empresário imitador local, burlando as regulamentações de marcas e patentes, iniciou a produção de "similares" de marcas famosas de tênis, especialmente a Nike. ${ }^{4} \mathrm{O}$ sucesso comercial desse tipo de produto deu origem a um processo, que, por fim, se revelou virtuoso, de aprendizado e disseminação de conhecimento na fabricação de tênis. A partir dessa origem obscura, a fabricação de tênis atraiu muitas outras empresas, e a história do pólo mudou, verificando-se uma guinada em sua evolução. Hoje a produção de tênis respon- 
de pela quase totalidade da produção de calçados de Nova Serrana, que participa com cerca de $55 \%$ da produção nacional. A falsificação foi reduzida a cerca de 3\% da produção, o que equivale a cerca de 10 mil pares/dia. ${ }^{5}$

\section{6_Estrutura da produção e forma de organização industrial}

O sistema local de produção de calçados de Nova Serrana comporta entre 850 e 900 empresas, ${ }^{6}$ das quais 368 eram associadas ao Sindinova em 2002. A distribuição das empresas por tamanho, segundo os dados da RAIS/2002, mostra grande predominância de micro/pequenas empresas: 70,5\% dos estabelecimentos das classes "Fabricação de tênis de qualquer material" e "Fabricação de calçados de outros materiais" no município de Nova Serrana empregam até 9 pessoas. Há apenas 7 empresas com mais de 100 empregados nessas duas classes de indústria. Isso é confirmado pelos resultados das entrevistas, que indicam um universo composto por algumas empresas de porte médio e grande número de micro/pequenas empresas.

Essas empresas produzem um total aproximado de 330 mil a 350 mil pares/dia. A quase totalidade da produção é de tênis, o que caracteriza o sistema local como altamente especializado nesse tipo de calçado. Mas há também considerável produção de chinelos e sandálias, fabricados predominantemente com material sintético. Como esse tipo de produto é geralmente de baixo valor, especialmente os chinelos, sua participação no total do valor da produção local de calçados é pouco expressiva.

Essa especialização na produção de tênis e outros calçados de material sintético explica a ausência, em Nova Serrana, de alguns segmentos da cadeia produtiva e a pequena presença de outras classes de atividades que compõem o sistema local de produção, tais como máquinas e equipamentos. A principal matéria-prima - resinas termoplásticas para produção de solados - é adquirida dos pólos petroquímicos de São Paulo, da Bahia e do Rio Grande do Sul e é fornecida por distribuidores locais às empresas fabricantes de calçados que a encaminham a empresas especializadas na injeção de solados. Alguns componentes mais simples são produzidos localmente, mas com matéria-prima de fora da região. Este é o caso, entre outros, de cadarços, etiquetas (enfeites e adesivos de plástico), palmilhas, caixas de papelão, componentes de borracha e de espuma. Componentes
5 Segundo um dos entrevistados, os falsificadores remanescentes são de dois tipos: o da empresa que "quebra" e volta na informalidade, falsificando (que o folclore local chama de "ressurreição"), e o da empresa que falsificou uma vez e ficou "viciada".

6 O levantamento estatístico feito pelo Sindinova aponta um total de 854 empresas em fins de 2001/início de 2002 , mas, um folheto de divulgação que circulou no próprio sindicato em abril de 2002, mencionava 900 empresas. 


\footnotetext{
......................

Incluindo todas as máquinas do processo de injeção, fabricação e montagem; matérias-primas como TR, PU, PVC, EVA, cola, nylon, curvim, linhas, tecidos; componentes de metais, e caixas de papelão (cuja origem é principalmente Jaú (SP).

8 As poucas que têm, segundo informações colhidas nas entrevistas, compram máquinas injetoras usadas, provavelmente obsoletas, $\mathrm{o}$ que implica menor produtividade e maiores custos de produção.

9 Com a recente mudança na legislação tributária da COFINS, o custo desse serviço deve ter sido onerado e repassado para os fabricantes locais de tênis.
}

de couro têm maior conteúdo local, assim como alguns dos equipamentos, como facas e navalhas para balancins e matrizes para solados. Mas a maior parte dos componentes, das matérias-primas, das máquinas e dos equipamentos é fornecida por empresas que não são da região. ${ }^{7}$

Os dados da Tabela 1 comprovam que apenas duas das classes de indústria que compõem o sistema local de produção de calçados têm indicadores incontestáveis de forte concentração na microrregião que inclui Nova Serrana, a saber: as de "fabricação de tênis de qualquer material" e as de "fabricação de calçados de outros materiais". Outras classes de indústria que fazem parte do sistema estão presentes na região, mas com indicadores menos significativos de concentração. São elas: fabricação de acessórios de vestuário, curtimento e preparação de couro, artefatos de couro, calçados de couro, calçados de plástico, embalagens de papel e papelão, artefatos de borracha, artefatos de plástico e máquinas para indústria de vestuário e calçados.

Nesse sentido, as inter-relações produtivas são relativamente fracas no sistema local de produção de calçados de Nova Serrana e municípios vizinhos.
Entretanto, uma característica notável da organização industrial desse sistema é a divisão de trabalho entre fabricantes de calçados e empresas especializadas na produção de solados ("injetoras", no jargão local). Essas empresas, em número de 30 a 50, conforme as fontes locais, operam com máquinas injetoras que têm, cada uma, capacidade de produção de 1.000 pares/dia de solados. As maiores chegam a ter 25 máquinas injetoras.

Uma vez que os fabricantes de calçados, em sua maioria, não têm escala para produção própria de solados, ${ }^{8}$ essa divisão de trabalho torna possível a realização de importantes ganhos de escala por parte do conjunto dos fabricantes de calçados locais. Mas o que é mais notável em termos de organização industrial é a classificação das empresas injetoras, do ponto de vista fiscal, como prestadoras de serviços aos fabricantes de calçados. Estes compram as matériasprimas, entregam-nas às injetoras junto com as matrizes dos solados a ser produzidos, e pagam pelo serviço prestado de injeção dos solados. Isso reduz a carga tributária na cadeia produtiva, já que as injetoras não pagam IPI; pagam apenas o ICMS sobre o valor agregado.? 
Tabela 1_ Microrregião de Divinópolis - Indústria de Calçados e Correlatas, 2002

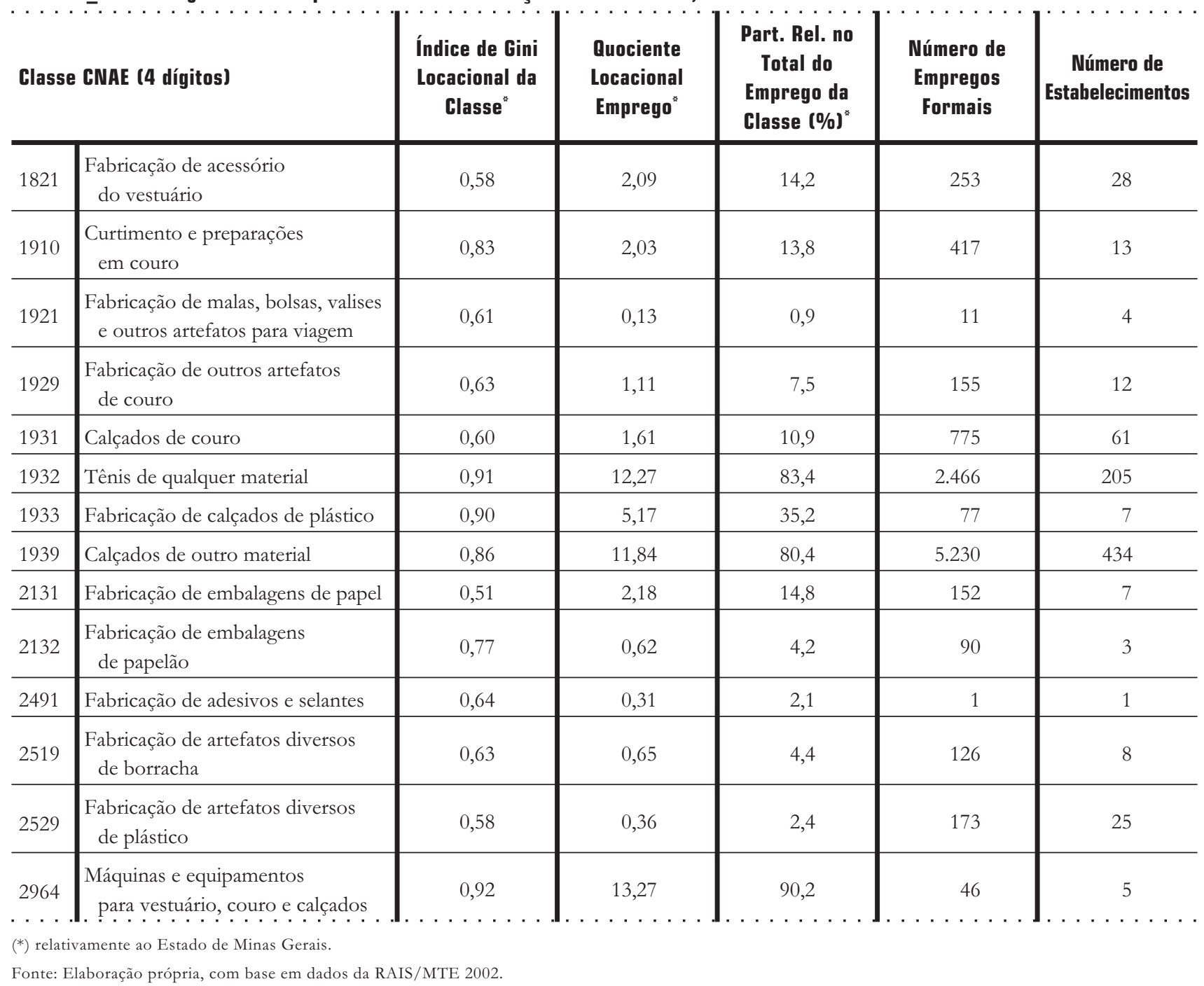


Trata-se, portanto, de uma inovação organizacional que proporciona ganhos de escala na fabricação de calçados, independentemente do tamanho das empresas e da estrutura da indústria; tira das fábricas de calçados uma fase do processo de produção que é estranha à fabricação de calçados propriamente dita, já que a injeção dos solados é um processo químico; reduz impostos na cadeia produtiva, e ainda reduz custos de produção. Em contrapartida, implica problemas de várias ordens, quais sejam: pode ocorrer comprometimento da qualidade dos solados, uma vez que é comum haver, por parte das injetoras, mistura de matériasprimas de qualidade inferior à que foi enviada para injeção; pode haver perda de controle sobre as matrizes (moldes), que correm o risco de ser repassadas pela empresa injetora a outros fabricantes de calçados, e pode haver atraso na entrega dos solados, provocando interrupções e atrasos na produção de calçados.

Portanto, apesar de ser uma inovação organizacional importante, a terceirização da produção dos solados pode resultar em perda de controle do processo de produção e spillover de novos conhecimentos embutidos no desenvolvimento de produtos, incorporados em novas formas e designs de solados, ou na utilização de novos tipos de material. Para evitar esses problemas, seria necessário que o sistema local de produção de calçados dispusesse de uma estrutura de governança capaz de coordenar as relações entre as empresas e de administrar conflitos. $\mathrm{Na}$ época em foi realizada a pesquisa de campo, tal estrutura não existia em Nova Serrana, mas começou a ser formalizada a partir de 2003 sob a liderança do Sindinova, como se discute adiante.

\section{7_ Instituições de apoio}

Além da Associação Comercial e Industrial de Nova Serrana (ACINS), que teve papel relevante como organização representativa da classe empresarial de Nova Serrana a partir de 1974, a única outra instituição atuante no apoio às empresas locais é o Sindicato da Indústria do Calçado de Nova Serrana (SICNS - Sindinova). Embora não se constitua formalmente em agente coordenador, o Sindinova mobiliza a classe empresarial, coordena de fato várias ações coletivas das empresas e desempenha diversos papéis relevantes. A principal iniciativa do Sindinova foi a criação do Centro de Desenvolvimento Empresarial (CDE), inaugurado em junho de 1996. 
O CDE funciona nas modernas instalações onde também se localiza a própria sede do Sindinova. Além de abrigar, na época da visita, o Showroom Permanente do Calçado de Nova Serrana, ${ }^{10}$ posteriormente desativado, o CDE mantém instalações de laboratório para testes físicos e um centro de modelagem, e presta vários tipos de serviço às empresas (Figura 1).

\section{Figura 1_Estrutura do Centro de Desenvolvimento Empresarial (CDE), Nova Serrana}

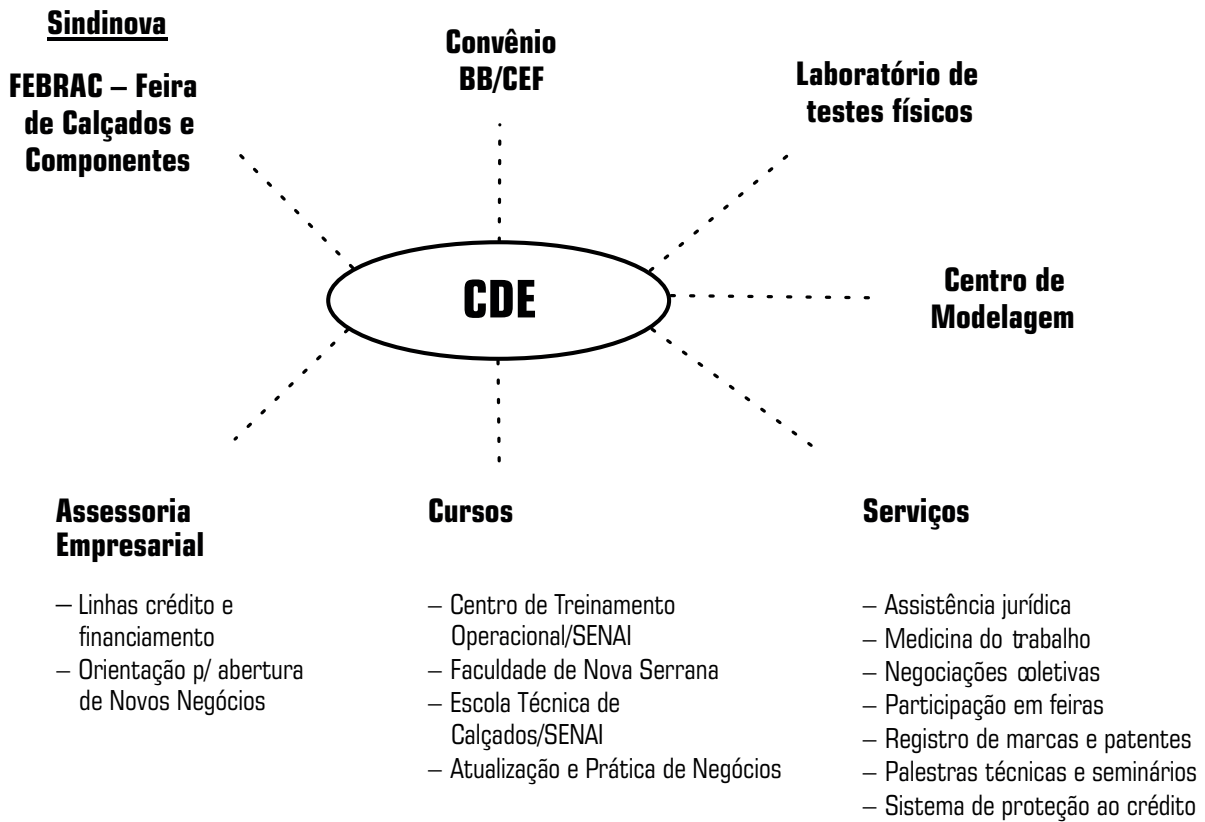

Fonte: Elaboração própria.

\author{
10 A criação do shomroom foi \\ iniciativa de um grupo de 14 \\ empresários locais que se \\ uniram instituindo a União \\ Calçadista de Nova Serrana \\ (UNICANS). Por meio da \\ UNICANS, buscaram \\ mobilizar recursos e encontrar \\ espaço para o showroom. O \\ apoio da Prefeitura de Nova \\ Serrana, segundo fontes \\ locais, foi "decisivo e vital" \\ para concretizar essa \\ iniciativa. Posteriormente, o \\ Sindinova assumiu o showroom, \\ e a UNICANS se desfez.
}


$\ldots \ldots \ldots \ldots$

11 Em exposição durante evento realizado em fevereiro de 2004, o presidente do Sindinova, Júnior César Silva, afirmou que o laboratório de ensaios "será assumido pelo Senai".

12 Segundo o Sindinova, o sistema CAD/CAM do CDE atende, em média, 160 empresas por mês, inclusive empresas de outros municípios.
O laboratório de testes físicos permite que as empresas associadas que não dispõem de laboratórios próprios realizem testes de qualidade e resistência (tração, flexão, abrasão, colagem) em calçados e diversos tipos de material. Os testes oferecidos incluem ensaios em couro, laminados sintéticos, solados, e no próprio calçado, abrangendo assim todo o processo de fabricação. Em 2001 e 2002, eram realizados cerca de 540 testes por ano. Entretanto, o próprio sindicato reconhece que o laboratório ainda é pobre e subutilizado. Um dos problemas é não dispor de certificação do INMETRO, o que permitiria atribuir um selo de qualidade ao calçado que passa pelos testes de laboratório do CDE. ${ }^{11} \mathrm{O}$ centro de modelagem, por sua vez, opera um sistema CAD/CAM de corte a laser para desenvolver escalas e realizar cortes de modelos para calçados, cobrando R\$120,00 por modelo (abril de 2002). Como a maioria das empresas locais não tem escala nem recursos para dispor de sistemas próprios de CAD/CAM, esse equipamento tem sido amplamente utilizado, propiciando significativas economias externas às empresas associadas. ${ }^{12}$

Quanto aos serviços prestados, incluem, entre outros:

1. cursos profissionalizantes, tais como o curso de pesponto, ofereci- do desde 1992 em parceria com o Senai, e o curso do Cefet Escola Técnica de Calçados, que desde 2001 forma técnicos em produção de calçados, estilismo e modelagem, administração e gerenciamento. Além disso, encontrava-se em negociação com o Senai um convênio denominado Projeto CTO para montagem de cursos para a formação de 2.160 alunos por ano;

2. curso de atualização e prática de negócios, em convênio com a Fundação Getúlio Vargas;

3. cursos da Escola Técnica de Formação Gerencial (ETFG), em convênio com o Sebrae/MG e a Prefeitura Municipal;

4. serviços do Núcleo de Atendimento Tecnológico, também em convênio com o Sebrae/MG;

5. Balcão Comex, com serviços de orientação para exportação;

6. Balcão Sebrae/MG, com serviços de orientação para abertura de novos negócios, para utilização de linhas de crédito e financiamento para micro/pequenas empresas, e para utilizar os recursos do Programa de Apoio Tecnológico a Médias e Pequenas Empresas (PATME - MCT); 
7. serviços gerais de assistência jurídica, registro de marcas e patentes, palestras técnicas e seminários, negociações coletivas, participação em feiras, ações de medicina do trabalho, sistema de proteção ao crédito, provedor de internet, e home page com dados dos associados e seus produtos.

Ainda no âmbito do CDE, duas outras importantes iniciativas coletivas foram lideradas pelo Sindinova. A primeira foi a de formar um Consórcio de Exportação. Para isso, buscou o apoio do Sebrae e da APEX. A ampliação das exportações era vista como um desafio em 2002, quando, segundo os empresários entrevistados, não passavam de 3\% da produção. Não mais do que 30 empresas, e apenas as de maior porte, exportavam esporadicamente. Embora não haja informação suficiente, há indícios de ampliação das vendas ao mercado externo, especialmente para países da América Latina. ${ }^{13}$ A outra iniciativa foi a realização de entendimentos com a Prefeitura $\mathrm{Mu}$ nicipal e uma fundação privada local, visando à criação da Faculdade de Nova Serrana. O objetivo era preencher uma séria lacuna no sistema de ensino local, já que não havia uma instituição de ensino superior no município.
Outra instituição que desempenha papel importante no apoio às empresas locais é a Cooperativa de Crédito de Nova Serrana (Credinova). Fundada em 1997 por um grupo de empresários locais, evoluiu rapidamente e, em 2001, já contava com 606 associados. É considerada atualmente a quarta maior cooperativa de crédito do Estado. Tem convênios com vários bancos, presta serviços bancários aos associados, e opera por meio de desconto de cheques e títulos. Além disso, oferece apoio aos associados para participação em feiras e realização de cursos e treinamentos.

\section{Contexto social, cultural e político}

Constituída por grande número de pequenas empresas, a indústria de calçados de Nova Serrana apresenta características positivas em termos de associativismo, solidariedade e papel de lideranças locais, mas há pouca cooperação na esfera produtiva ${ }^{14}$ e problemas decorrentes de deficiências do sistema educacional local e da imagem do produto. O associativismo se revela na forte adesão das empresas ao Sindinova e no grande número de associados da Credinova (comentado acima). No caso do Sindinova, em 2002
13 Conforme informações divulgadas pela FIEMG, Projeto Cresce Minas, e pelo Instituto Euvaldo Lodi.

14 Ver seção seguinte, sobre a caracterização das empresas. 
15 Conforme entrevista

com o presidente do

Sindinova, Júnior César

Silva, em 24/4/2002.

O mesmo evento foi relatado por vários empresários locais durante as entrevistas. havia 368 empresas sindicalizadas, de um total estimado, à época, de 854 empresas, entre as quais cerca de dez por cento eram microempresas informais fabricantes de tênis falsificados. Portanto, aproximadamente metade das empresas formais era sindicalizada. Isso resultou não só do reconhecimento de lideranças locais que dirigiam o sindicato como também de um meticuloso trabalho político desenvolvido pela própria instituição, que contratou um profissional com ampla experiência na área e encarregou-o de visitar empresas e obter adesões.

O espírito de solidariedade, por sua vez, manifesta-se por meio de práticas comuns em aglomerações como a de Nova Serrana: empréstimos de máquinas, material, etc., mesmo quando se trata de abertura de novas empresas, e sobretudo em situações emergenciais. Dois casos parecem ter significado especial na cultura da cidade: o do incêndio que destruiu a fábrica de uma empresa local (Calçados Adam), motivando a solidariedade de outros empresários, que "se juntaram para ajudar", emprestando máquinas e matérias-primas..$^{15}$ Segundo Crocco et al. (2001, p. 358), em uma semana, a empresa voltou a produzir. O outro caso foi um golpe aplicado nos fabricantes do município por uma rede varejista de Belo Horizonte, que, após construir rela- ções de confiança com os produtores, acumulou débitos e desapareceu, quebrando algumas pequenas empresas locais que tiveram que ser socorridas para reiniciar as atividades.

Entretanto, apesar do associativismo e do espírito de solidariedade, são ainda fracas as relações de cooperação entre fabricantes de tênis na esfera produtiva. Prevalece o espírito de competição na disputa por mercados com base na diferenciação e no desenvolvimento de produtos próprios. Isso é bastante saudável do ponto de vista da evolução do sistema local de produção, mas limita as possibilidades de esforços coletivos para aprimoramento de processos, incorporação de novas técnicas produtivas e gerenciais, e busca por informações sobre mercados, tecnologias e novos produtos.

Para que haja maior cooperação entre fabricantes e destes com as instituições locais, especialmente as da esfera política, é necessário um processo de construção de confiança, o que vem sendo buscado pelo Sindinova em colaboração com a Federação das Indústrias de Minas Gerais (Fiemg) e outras instituições, por meio de um projeto de desenvolvimento que:

1. reforça a identidade comum, criando uma logomarca; 
2. desenvolve ações estratégicas delineadas por um comitê gestor no qual participam representantes de poderes públicos, instituições de apoio, universidades e centros de pesquisas, entidades de fomento e empresas locais. ${ }^{16}$

Há também deficiências no sistema educacional e de formação profissional, que se revelam na falta de trabalhadores qualificados (um exemplo muito citado nas entrevistas é o da falta de pespontadeiras, como já comentado), na carência de profissionais especializados (principalmente modelistas e designers), e sobretudo em deficiências de capacitação gerencial e operacional. Os próprios empresários reconhecem a necessidade de "cursos para melhorar o conhecimento dos empresários sobre o setor de calçados". As facilidades que o próprio ambiente oferece para iniciar uma nova empresa, muitas vezes com ajuda das empresas existentes, e o fato de que a maioria dos novos empresários é oriunda das linhas de produção das empresas locais explicam, em grande parte, as dificuldades na gestão das novas empresas.

Ligado a este último fenômeno, há também um problema de imagem que tem a ver com a cultura local sobre a criação de empresas. Segundo um dos entre- vistados, para iniciar uma nova fábrica, é bastante comum que a pessoa conte com "um galpão emprestado, máquinas que vieram de outra empresa", e que comece "com pequena produção (cerca de 100 pares/dia) e vai investindo os lucros em novas máquinas". Assim, ele "tem dois caminhos: ganhar dinheiro rápido ou ficar no mercado". Isso significa entrar no mercado pela informalidade e, de acordo com esse entrevistado: "continuar na informalidade, produzindo tênis falsificados, ganhar dinheiro e sair, ou deixar a informalidade e a falsificação para manter-se no mercado". Esse problema já foi bastante minorado, mas ainda persiste e prejudica a imagem da indústria de calçados de Nova Serrana.

\section{9_Caracterização das empresas}

Foram realizadas visitas e entrevistas em 12 empresas, das quais três "grandes", que empregam entre 90 e 110 pessoas e produzem entre 1.000 e 1.600 pares/dia; três "médias", com 30 a 60 empregados e produção entre 500 e 1.000 pares/ dia, e 6 micro/pequenas, com menos de $30 \mathrm{em}-$ pregados e produção de menos de 1.000 pares/dia. ${ }^{17}$ Duas foram fundadas na década de 1980, e as demais entre 1990 e 1999. A maior parte produz tênis, mas

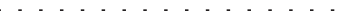

16 Conforme exposição do presidente do Sindinova, Júnior César Silva, no evento Desenvolvimento Econômico e a Micro e Pequena Empresa, Programa de Estudos

Avançados para Líderes Públicos. Londrina, PR, 5 e 6 de fevereiro de 2004. Ver também a esse respeito, a excelente dissertação de mestrado de Souza (2004).

17 Optou-se por uma classificação por tamanho das empresas visitadas que levasse em conta as especificidades do universo local, dado pelas informações da RAIS. Por isso, as designações como "grandes" e "médias" empresas estão entre aspas. Os autores reconhecem que, conforme observado por um dos pareceristas da Nova Economia, esse procedimento limita as possibilidades de comparação com outros pólos calçadistas. Entretanto, julgam que não há no País sistemas de produção comparáveis com Nova Serrana em termos de especialização produtiva, estratificação por tamanho de empresas e forma de organização industrial. 
uma produz apenas sandálias e outra estava começando a diversificar a produção, iniciando uma linha de calçados de couro. Quase todas vendem exclusivamente para o mercado interno; apenas uma exporta esporadicamente para países da América Latina.

Somente duas das maiores empresas têm alguma formalização de estrutura interna para desenvolvimento de produtos, entretanto ainda muito limitadas. A maioria contrata o desenvolvimento por terceiros, em geral modelistas locais, das quais havia carência em 2002. Segundo um dos entrevistados, havia cerca de 10 modelistas na cidade, e outro afirmou que "falta muito modelista em Nova Serrana", o que ele atribuía à "dificuldade para se adaptar ao local". Algumas empresas se unem para contratar modelista e lançam o mesmo tipo de produto. Duas das empresas menores usam o sistema CAD do CDE.

Entretanto, "por desenvolvimento de produto", entenda-se adaptação de modelos existentes no mercado, em geral importados. Um dos entrevistados declarou que a prática usual é a cópia. Em geral, segundo ele, a empresa compra um tênis de marca famosa e "corta no meio para ver como é montado".

As formas de comercialização dos produtos e as estratégias de diferenciação são ainda muito incipientes. Com exceção de duas das maiores empresas, que vendem para grandes varejistas ou para lojistas, possuem marca própria e dão atenção à qualidade; as demais não têm canais próprios de comercialização, vendem por meio de representantes ou direto na fábrica, a maior parte para os chamados "marreteiros", e competem primordialmente via preços, ficando a qualidade em segundo plano.

As relações de cooperação produtiva entre as empresas são muito limitadas, em geral envolvendo "só as que se conhecem" ou "amigos que não são concorrentes". É comum, porém, a prática de empréstimos de máquinas e matérias-primas, assim como a formação de pequenos grupos de empresas para a realização de algumas operações de compra, contratação de modelista, negociação de fretes, realização de cursos, participação em feiras. São também comuns as visitas para "ver máquinas novas" e a troca de idéias e de informações. Apenas no âmbito do CDE, no entanto, pode-se dizer que há cooperação de fato entre as empresas locais.

As interações das empresas locais com seus fornecedores são dificultadas pelo fato de que boa parte desses fornecedores não é de Nova Serrana e até mesmo do Estado de MG, como já foi discutido 
acima. Há contatos com fornecedores para discutir, por exemplo, cores, utilização de novos tipos de material, e com representantes e lojistas para recolher sugestões quanto a desenvolvimento de produtos. Entretanto, pelas características da organização da indústria local, é a interação com os fabricantes de matrizes e com as empresas especializadas na injeção de solados que se revela de importância estratégica. Não só porque envolve a proteção de conhecimentos sobre novos tipos e designs de solado, como também porque é preciso estabelecer relação de confiança entre as partes, de modo a evitar que haja misturas inadequadas de matériasprimas e atrasos na injeção dos solados, o que faria parar a linha de produção de tênis. Quase todas as empresas ressaltaram ser essa a forma de interação a que dão mais importância.

Apesar das limitações das empresas quanto a desenvolvimento de novos produtos, a introdução de inovações de produto ou de processo é uma preocupação constante das empresas. Embora declarem sem peias que a cópia pura e simples é a prática mais usual, muitas afirmam também que buscam informações sobre produtos e processos em várias fontes, entre as quais: fornecedores de máquinas, visitas a feiras (inclusive no exte- rior), publicações especializadas (catálogos, revistas), sugestões de representantes e lojistas, visitas a shopping centers e ainda com os próprios modelistas contratados.

Quanto à política da qualidade, a maior parte da empresas realiza testes da qualidade dos produtos, seja internamente (duas das maiores), seja nas instalações do laboratório de testes físicos do CDE (9 das 10 empresas restantes). Uma das empresas grandes declarou ter certificação ISO 9002, e outra estava tentando obtê-la. Portanto, a preocupação com a qualidade parece disseminada, a ponto de um dos entrevistados dizer que "qualidade já não é diferencial, todo mundo tem que ter". Mas está limitada na maior parte das empresas ao produto final; poucas empresas declararam ter uma política da qualidade mais abrangente da cadeia produtiva ou um programa da Qualidade Total.

Por fim, praticamente todas as empresas têm dificuldades quanto a financiamento. Investimentos são financiados com recursos próprios e, em poucos casos, com crédito de fornecedor de máquinas. As queixas são generalizadas quanto a juros muito elevados, exigências de garantias muito altas, burocracia, etc. No capital de giro, os recursos próprios são complementados com descontos bancários e pequenos empréstimos. 


\section{0_Conclusões}

Este artigo mostra que a indústria de calçados de Nova Serrana ocupa posição inegavelmente destacada na economia da região e, em particular, na produção de tênis esportivos no Estado de Minas Gerais e no País. Sua evolução foi impulsionada com base na especialização nessa classe de indústria, na adoção de formas específicas de organização industrial e de um papel ativo do sindicato patronal no apoio à indústria, particularmente após a criação de um centro tecnológico e de prestação de serviços às empresas. Os desafios que se colocam ao desenvolvimento do sistema local de produção vêm sendo enfrentados por novas iniciativas coordenadas pelo sindicato, com apoio e participação de outras instituições.

Vários problemas, entretanto, persistem. Primeiro, permanece um número elevado de microempresas informais fabricantes de tênis falsificados. Embora a quantidade tenha sido bastante reduzida em relação ao passado, continua sendo um problema que prejudica a imagem da indústria de calçados de Nova Serrana. Segundo, há notórias deficiências em termos das chamadas capacitações técnicas superiores, o que, por sua vez, reflete insuficiências do sistema educacional e de formação profissional da região. Isso implica dificuldades para as empresas engajarem-se em atividades de pesquisa e desenvolvimento de novos produtos, utilizarem material mais avançado, melhorarem a qualidade total e, com isso, tornarem-se mais capacitadas a diferenciar e valorizar o seu produto. Terceiro, os sistemas de comercialização da produção local tornam as empresas reféns da competição via preço baixo; é preciso desenvolver formas de comercialização compatíveis com a valorização do produto. Quarto, embora haja elevado associativismo e manifestações de solidariedade, há pouca cooperação em sentido amplo entre as empresas fabricantes de produtos finais.

Dado o grande número de micro e pequenas empresas na estrutura produtiva local, a indústria de calçados de Nova Serrana constitui campo fértil para ações coletivas sob algum regime de governança que induza a cooperação entre empresas e destas com instituições de apoio, sistema educacional, centros de pesquisa e setor público. Esses são alguns dos pontos que podem ser alvos de políticas públicas e ações privadas, visando aumentar e sustentar a capacidade de competição do sistema local de produção de Nova Serrana. 


\section{Referências bibliográficas}

ALMEIDA, J. S. História do calçado. Nova Serrana, CDE, 1996. (brochura).

CASSIOLATO, J. E.; LASTRES, H. M. M. O foco em arranjos produtivos e inovativos locais de micro e pequenas empresas. In: LASTRES et al. (Orgs.).

Pequena empresa: cooperação e desenvolvimento local. Rio de Janeiro: Relume Dumará, 2003.

CROCCO, M.; SANTOS, F.; SIMOES, R.; HORACIO, F. O arranjo produtivo calçadista de Nova Serrana. In: TIRONI, L. F. (Coordenador). Industrialização descentralizada: sistemas industriais locais. Brasília: IPEA, 2001.

LOMBARDI, M. The evolution of local production systems: the emergence of the "invisible mind" and the evolutionary pressures towards more visible "minds". Research Policy, v. 32, n. 8, p. 1.443-1.462, 2003.

SOUZA, C. R. de Oliveira. Redes interorganizacionais em um arranjo produtivo local: uma estratégia para o desenvolvimento regional. 2004. Dissertação (Mestrado em Administração) - (Curso de Mestrado Profissional em Administração) FEAD Minas, Centro de Gestão Empreendedora, Belo Horizonte, 2004.
SUZIGAN, W.; FURTADO, J.; GARCIA, R.; SAMPAIO, S.

Coeficientes de Gini Locacionais - GL: aplicação à indústria de calçados do Estado de São Paulo. Nova Economia, v. 13, n. 2, p. 39-60, jul./dez. 2003.

$\because \cdot \cdot \cdot \cdot \cdot$ - Os autores agradecem o apoio - financeiro do CNPq por meio : de auxilio pesquisa (Processos - 466034/2000-8

- e 478786/2003-4) e de bolsa - PIBIC para a estagiária - Ana Paula Munhoz Cerrón. - Agradecem também a dois - pareceristas anônimos por - comentários e sugestões que - permitiram aprimorar o artigo.

E-mail de contato dos autores:

- wsuzigan@ige.unicamp.br

- jfurt@uol.com.br

renato.garcia@poli.usp.br

- seksampa@gmail.com

............. 